\title{
Basic flaw in new UK councils?
}

London. British physicists have complained to the government that the terms of reference of the new Engineering and Physical Sciences Research Council (EPSRC) do not contain an explicit commitment to promoting basic science. As a result, they fear that research in fields such as nuclear physics and mathematics could be threatened if the council leans too far towards its efforts to boost the nation's immediate capacity for wealth creation.

The warning comes in a letter from Alun Jones, chief executive of the Institute of Physics, to the minister responsible for science, William Waldegrave. It follows the government's decision that, when the Science and Engineering Research Council (SERC) is divided up next year along the lines proposed in the recent white paper (policy document) on science, responsibility for supporting physics research will be split between two funding agencies. Highenergy and space physics will come under the new Particle Physics and Astronomy Research Council (PPARC), which will in particular take over responsibility for Britain's contribution to CERN, the European Laboratory for Particle Physics. But nuclear physics, together with disciplines such as chemistry and mathematics, will in future receive support through the EPSRC.

Most practising nuclear physicists, according to an informal survey by the SERC's nuclear physics committee, had been opposed to this split. Their argument was that, from a scientific point of view, nuclear physics is closer to particle physics than to the other disciplines falling under the aegis of the EPSRC, and the relationship is likely to develop further as nuclear physics moves to higher energies.

In policy terms, however, the split makes more sense. Nuclear physics research tends to be more closely related to engineering applications than to high-energy physics. And many welcome the fact that they will no longer find themselves in direct competition for funds with the particle physics community, which has to pay for Britain's contribution to CERN.

While accepting the logic of the new arrangements, however, physicists are also concerned that, while the PPARC will be required as part of its proposed mission statement to promote "improved understanding of the concepts and principles underlying physical phenomena", no such clause exists in the suggested wording of the charter of the EPSRC.

The institute's letter to Waldegrave says that uncertainty over whether the new council will give adequate support for basic science "is leading to anxiety" among physicists, and asks for a formal statement clarifying the government's position. "If funds for basic research are constrained, this will have a detrimental effect on the achievement of the white paper's goals", says Jones.

Officials in Waldegrave's Office of Science and Technology point out that the white paper explicitly states that all the new research councils (apart from the PPARC) will be responsible for supporting both basic and applied research. But they acknowledge that the effect of favouring research that contributes to wealth creation will inevitably mean a shift in funds from the former to the latter.

They also defend the decision to ensure that, even where basic research is supported by these research councils, it is done so within a framework that is acceptable to the industrial community. Ad- dressing the House of Lords Committee on Science and Technology last month, for example, Waldegrave described this as one of the reasons for his decision - still being widely viewed with concern in the scientific community - to appoint senior industrial figures as the part-time chairpersons of the research councils.

But even industrialists are warning of the dangers of moving too enthusiastically in the direction of seeking an identifiable pay-off from investments in science. "We approve of the new emphasis on the importance of science in wealth creation," says Clive Foxall, president of the Institute of Physics and a former managing director of British Telecom. "We just don't want the pendulum to swing too far."

David Dickson

\section{Japan opens supercomputer bidding}

Tokyo. The Japanese government has set up an elaborate process to ensure that the imminent procurement of 11 supercomputers for its government research institutes and universities is carried out in an open and fair manner.

The move follows concern expressed last month by Mickey Kantor, the US trade representative, that contracts for four new supercomputers already being funded from the 1993 budget have all been won by Japanese suppliers, despite the strength of American producers of such machines.

The four machines will go to Tohoku University, the Institute of Space and Astronautical Science, the Okazaki national research institutes and the Meteorological Research Institute in Tsukuba.

All four are being funded from the regular budget. The additional 11 supercomputers are being purchased under a supplementary budget designed to help pull Japan out of its current recession, and represents the biggest such procurement ever made by the government.

According to Kantor, the United States will be watching carefully to see whether these procurements comply with the 1990 agreement between Japan and the United States on supercomputer trade. In response, Japan's Ministry of Trade and Industry (MITI), for example, has already appointed an experienced trade negotiator, Tadatsune Koda, to oversee the procurement of one of the three supercomputers it has been allocated. (The other two are being purchased by a consortium of companies in charge of MITI's new large-scale project on nanotechnology.)

Koda is director general of the general coordination division of MITI's Agency of Industrial Science and Technology
(AIST). He says that he is determined to ensure that MITI's procurement process is "transparent", that technical criteria are "clear" and that "due process" is observed. Koda heads a procurement committee consisting of the heads of the AIST's 15 research institutes. The committee has in turn set up a working group of research directors from those institutes that will be connected to the supercomputer, which will be based at the agency's supercomputer centre in Tsukuba and used as the centre of a communications network

Manufacturers interested in bidding for this supercomputer were given a preliminary explanation of the agency's requirements on 27 July. They have been given until the middle of September to submit comments on the specification, and the process will then be open for bids for a further 50 days.

According to MITI, a final decision on the choice of manufacturer will be made towards the end of the year by the head of the Tsukuba supercomputer centre, with the intention of installing the machine in March. Similar procedures will be followed by the Science and Technology Agency and four other ministries involved in the supercomputer procurement, as well as by the consortium running MITI's nanotechnology project.

Cray is planning to bid for 10 of the 11 new supercomputers. According to a report in the industrial newspaper Nihon Kogyo Shimbun, the US manufacturer stands a good chance of winning at least two of the bids for computers at MITI's institutes.

The newspaper also lists Digital Equipment Corporation (DEC) Japan, the Japanese subsidiary of the US maker DEC, as the strongest competitor for a massively parallel system for a DNA database at the National Institute of Agrobiological Resources, where Japan's rice genome project is centred. DEC is also a leading candidate for a cancer database at the National Cancer Centre.

David Swinbanks 